\title{
CANCER MORTALITY IN GREECE: WHERE ARE WE HEADING? A 20-YEAR COMPARATIVE STUDY IN FOUR GREEK COUNTIES
}

\author{
Zeppos Mostratos, Philip R. Domeyer, Dimitrios Michalis \\ Aliartos Health Centre, Voiotia, Greece
}

\section{SUMMARY}

Aim: Comparison of cancer mortality rates in four Greek counties during the decades 1979-1988 and 1989-1998 and drawing out of cause and effect relationships that could lead to organization of prevention programs.

Methods: We used the Wilcoxon-White test to statistically compare data between the two decades as well as between the four counties separately.

Results: We found that the total proportional mortality during the decade 1988-1998 significantly increased, compared to 1979-1988, in all counties we studied. We noted a statistically significant increase of the proportional mortality of organs of the gastrointestinal tract and peritoneum ( $W=55, p<0.001$ for both decades), of the respiratory system and intrathoracic organs ( $W=71, p=0.009$ for 1979-1988 and $W=55, p<0.001$ for 1988-1998) and the skin and breast ( $W=136, p=0.019$ for 1979-1988) in Attiki compared to Thessaloniki. As far as Achaia and Trikala are concerned, we found a minor, though statistically significant increase of the proportional mortality of organs of the gastrointestinal tract and peritoneum $(W=78, p=0.043)$, of the respiratory system and intrathoracic organs $(W=77, p=0.035)$ and the skin and breast $(W=76, p=0.029)$ during the decade 1988-1998.

Conclusions: Statistically significant differences were noted concerning the incidence rates between four different counties as well as between two different decades. Although genetic factors might partially explain our results, environmental factors seem to be the main culprits.

Key words: neoplasms, mortality, Greece

Address for correspondence: Philip Domeyer, 2, Agiou Andreou Str., Nea Smyrni, Athens 17122, Greece. E-mail:jdomeyer@mail.ntua.gr

\section{INTRODUCTION}

The proportional mortality (PM) of a specific region is a statistical index that, like carcinogenesis, is influenced by many demographical, environmental, dietary and genetic factors. The $\mathrm{PM}$ is equal to the number of deaths due to malignant neoplasms divided by the total number of deaths, multiplied by 100 . The PM is a key epidemiological index in order to carry out statistical analyses comparing the incidence of several cancer types among different geographic areas.

Greece has the lowest worldwide total cancer mortality rates for females $(78 / 100,000)$ together with France and Spain, whereas for males the lowest ones are found in Israel $(127 / 100,000)$ and Sweden $(130 / 100,000)(1)$.

The purpose of our study was to compare and analyze the PM in four Greek counties between the two decades in order to draw conclusions concerning the possible causes, which could potentially lead to the organization of prevention programs.

We statistically analyzed cancer mortality data concerning four major Greek counties; Attiki, Thessaloniki, Achaia and Trikala, between 1979 and 1998.

\section{MATERIALS AND METHODS}

The materials of this study were drawn from epidemiological reports of the National Statistical Service of Greece (2) on the number of cancer deaths related to etiology, time and demographical area. The cancer types included in our study are related to tissues and organs, grouped into seven categories (Table 1). We followed the grouping of the National Statistical Service of Greece, which uses the International List of 1975 (Liste Internationalle Abrégée de 1975) since data were provided to us accordingly.

We decided to focus our study on four major demographical Greek areas (Attiki, Thessaloniki, Achaia and Trikala) during the years 1979 to 1998 . Thessaloniki and Trikala are Northern Greek counties whereas Attiki and Achaia are Southern Greek counties.

These areas were chosen because they met the following criteria:

1. They stayed relatively homogenous concerning population size, age and sex, according to the data provided to us by the National Statistical Service of Greece (2).

2. Different geographical location.

Abbreviations: PM - Proportional Mortality, LOP - Lips, oral cavity and pharynx, GI - Organs of the gastrointestinal tract and peritoneum, RE - Organs of the respitatory system and intrathoracic organs, SKIN - Skin and breasts, URO - Organs of the urogenital system, LY-HE - Lymphatic and hemopoietic tissue, $\mathrm{W}$ - Wilcoxon index 
Table 1. Groups of tissues and organs that were studied for cancer development

\begin{tabular}{|c|l|c|}
\hline \multicolumn{2}{|c|}{ Groups of tissues and organs } & $\begin{array}{c}\text { Abbre- } \\
\text { viations }\end{array}$ \\
\hline 1. & Lips, oral cavity and pharynx & LOP \\
\hline 2. & Organs of the gastrointestinal tract and peritoneum & $\mathrm{GI}$ \\
\hline 3. & Organs of the respiratory system and intrathoracic organs & RE \\
\hline 4. & Skin and breast & SKIN \\
\hline 5. & Organs of the urogenital system & URO \\
\hline 6. & Lymhatic and hemopoietic tissue & LY-HE \\
\hline 7. & Other tissues and organs & OTHER \\
\hline
\end{tabular}

These decades were chosen assuming that the Chernobyl accident in 1986 might affect cancer mortality data and that the minimum time lapse for the accident's immediate consequences to take effect is 3 years.

The statistical analysis was based on the Wilcoxon test for unpaired measurements (Wilcoxon-White test, Mann-Whitney U-Test, Wilcoxon). We calculated the total cancer mortality rate as well as the mortality rate for every cancer type group during the decades 1979-1988 and 1989-1998 in each county and between several counties.

\section{RESULTS}

The total PM during the decade 1988-1998 significantly increased, compared to the decade 1979-1988, in all counties.

When comparing data between 1988-1998 and 1979-1988 in each county, we found that the PM fluctuations in the seven study groups differed (Table 2). When comparing data between Attiki and Thessaloniki and between Achaia and Trikala in each decade, we also noted various PM fluctuations in the seven groups. (Tables 3 and 4).

In Thessaloniki, we found that the PM of cancer of organs of the gastrointestinal tract and peritoneum increased compared to Attiki during both decades ( $\mathrm{p}<0.001)$. We also found that PM concerning organs of the respiratory system and intrathoracic organs increased compared to Attiki in the first decade

Table 2. Comparison of the PM due to all neoplasms between decades 1979-1988 and 1989-1998 in each county. The counties are sorted by descending order of statistically significant differences of the PM

\begin{tabular}{|l|c|c|c|}
\hline \multicolumn{1}{|c|}{ County } & W & p & $\begin{array}{c}\text { Statistically } \\
\text { significant } \\
\text { difference }\end{array}$ \\
\hline Thessaloniki & 56 & $<0.001$ & Yes \\
\hline Trikala & 61 & $<0.001$ & Yes \\
\hline Attiki & 61 & $<0.001$ & Yes \\
\hline Achaia & 70 & 0.007 & Yes \\
\hline
\end{tabular}

W= Wilcoxon index for the PM during the decade 1979-1988. $(\mathrm{p}=0.009)$. This increase became even more prominent in the second decade $(\mathrm{p}<0.001 \%)$. Moreover, we noted a clear increase in the PM of the skin and breasts in Thessaloniki, since during the decade 1979-1988 the PM of the skin and breast increased in Attiki $(\mathrm{p}=0.019)$ while, in the second decade, no such difference was noted (Table 3 ).

In Attiki, we found that only the PM concerning other tissues and organs was higher than in Thessaloniki during the decade 1989-1998 but, in the first decade, this difference was less important. (First decade Wilcoxon index $=155$, second decade index $=$ $15 ; \mathrm{p}<0.001)$ (Table 3).

When comparing Achaia and Trikala, we found that in the decade 1979-1988 no statistically significant difference was noted in any PM. However, in the decade 1989-1998, we found that the PMs of the organs of the gastrointestinal tract and peritoneum $(p=0.043)$, the respiratory systems and intrathoracic organs $(p=0.036)$ and the skin and breasts $(p=0.029)$ increased in Trikala compared to Achaia (Table 4).

\section{DISCUSSION}

Our study showed statistically significant differences of proportional mortality between four different counties and between two different decades. Counties of Northern Greece and, particularly Thessaloniki, compared to Attiki, have greater PMs than Southern Greek counties during the decade 1989-1998. In our study, we used proportional mortality, since no credible data exist concerning the population's size and characteristics. This also explains the inability to perform any kind of age standardization, the fact that proportional mortality could not be adjusted for sociodemographic factors and that "exposure" data were not available. Another great disadvantage of using this index is that it constitutes a complex expression of two factors, without specifying which of the two factors is changing. Thus, the total PM is inevitably affected by changes in cancer mortality as well as all-cause mortality.

Carcinogenesis is a multistep procedure involving a complex interaction between genetic and environmental factors. The genetic bases of cancer development are nowadays indisputable and may vary in different racial and ethnic groups coexisting in our country. Cancer mortality rates are also affected by patterns of early detection and by the quality of available medical care that may not be identical in all counties (3). In urban areas, there is a higher level of medical care, better access to medical facilities, information and education sources, which may affect cancer mortality rates. Moreover, the quality of treatment may have improved in regions with increased screening, contributing to additional declines in mortality. These factors could bias our results and are difficultly compensated. Other factors such as nulliparity and older age at first live birth are more prevalent among women in areas with high breast cancer death rates and could also affect our results. Finally, other factors complicating our research could be political, social and economic changes causing large-scale migrations. Greece has been experiencing a large immigration current from Albania since 1990, a country with a different socioeconomic status, which could affect cancer mortality rates in the second study decade as well as in geographic areas where immigration was more prominent. 
Table 3. Cancer groups and corresponding statistically or non-statistically significant increase of the PM during the decade 1988-1998 compared to the decade 1979-1988 in Attiki compared to Thessaloniki

\begin{tabular}{|l|c|c|c|c|c|c|}
\hline \multirow{2}{*}{ Groups } & \multicolumn{3}{|c|}{$1979-1988$} & \multicolumn{2}{c|}{ 1989-1998 } \\
\cline { 2 - 7 } & $\mathbf{W}$ & $\mathbf{p}$ & $\begin{array}{c}\text { Statistically significant } \\
\text { difference }\end{array}$ & $\mathbf{W}$ & $\mathbf{p}$ & $\begin{array}{c}\text { Statistically significant } \\
\text { difference }\end{array}$ \\
\hline TOTAL & 67 & 0.003 & Yes & 59 & $<0.001$ & Yes \\
\hline LOP & 100 & 0.739 & No & 86 & 0.166 & No \\
\hline GI & 55 & $<0.001$ & Yes & 55 & $<0.001$ & Yes \\
\hline RE & 71 & 0.009 & Yes & 55 & $<0.001$ & Yes \\
\hline SKIN & 136 & 0.019 & Yes & 102 & 0.853 & No \\
\hline URO & 118 & 0.353 & No & 105 & 0.971 & No \\
\hline LY-HE & 126 & 0.123 & No & 118 & 0.353 & No \\
\hline OTHER & 155 & $<0.001$ & Yes & 152 & $<0.001$ & Yes \\
\hline
\end{tabular}

W= Wilcoxon index for the PM of Attiki.

As far as the PM difference between Attiki and Thessaloniki and between Achaia and Trikala is concerned, any research of genetic differences between those populations would be extremely difficult. However, the research of environmental factors that may be responsible for such a difference, e. g. food quality, dietary habits, smoking habits, exposure to insecticides, pesticides and environmental radioactivity as well as drinking water quality seems more feasible. Recent studies, however, were unable to statistically correlate environmental radioactivity with cancer development (3-6).

Smoking is considered to be the major cause of lung cancer. However, the increase of smoking is a national phenomenon and would thus not account for the increase of the PM of the organs of the respiratory system and intrathoracic organs during the second study decade. Atmospheric pollution could also affect mortality rates, however our attempt to compare it between Attiki and Thessaloniki during the years 1979-1998 failed due to the lack of data for Thessaloniki up to 1990 . According to national reports, the total concentration of pollution gases in Attiki and Thessaloniki has been dropping since the onset of air pollution measurements (1984 and 1990 respectively).
The increasing exposure to insecticides and pesticides used in agriculture could also account for our results. Many insecticides and pesticides are considered potential carcinogens (7-9). The correlation between insecticides, pesticides and carcinogenesis concerning the substance's chemical nature and exposure's duration is still under investigation.

Another factor thought to account for variations in cancer mortality rates is diet. A diet rich in fat has been found to increase the risk of breast and colon cancer. Wynder et al. observed that the typical diet of Japanese, who have low breast cancer rates, is 10 to $25 \%$ calories from fat sources, whereas the diet of Americans - who have higher breast cancer rates - is 40 to $45 \%$ total calories from fat (10). However, some populations have high dietary fat intake without high breast cancer rates (3). To explain these findings, it has been suggested that monosaturated fat sources are actually protective and that risk is more specifically associated with polyunsaturated fat (11). This may explain the fact that countries such as Greece do not have the highest breast cancer mortality rates, in spite of relatively high fat consumption. However, the dietary differences between populations or between counties of the same country may be coincidental with many other differences

Table 4. Cancer groups and corresponding statistically or non-statistically significant increase of the PM during the decade 1988-1998 compared to the decade 1979-1988 in Achaia compared to Trikala

\begin{tabular}{|l|c|c|c|c|c|c|}
\hline \multirow{2}{*}{ Groups } & \multicolumn{3}{|c|}{$1979-1988$} & \multicolumn{2}{c|}{$1989-1998$} \\
\cline { 2 - 8 } & W & $\mathbf{p}$ & $\begin{array}{c}\text { Statistically signi- } \\
\text { ficant difference }\end{array}$ & W & $\begin{array}{c}\text { Statistically signi- } \\
\text { ficant difference }\end{array}$ \\
\hline TOTAL & 103 & 0.912 & No & 82 & 0.089 & No \\
\hline LOP & 112 & 0.631 & No & 116 & 0.436 & No \\
\hline GI & 88 & 0.218 & No & 78 & 0.043 & Yes \\
\hline RE & 105 & 0.971 & No & 77 & 0.036 & Yes \\
\hline SKIN & 124 & 0.166 & No & 76 & 0.029 & Yes \\
\hline URO & 130 & 0.063 & No & 106 & 0.971 & No \\
\hline LY-HE & 107 & 0.912 & No & 131 & 0.052 & No \\
\hline OTHER & 130 & 0.063 & No & 112 & 0.631 & No \\
\hline
\end{tabular}

W= Wilcoxon index for the PM of Achaia. 
and the correlation of diet with cancer risk does not necessarily represent proof of a causal relation $(3,12-15)$.

Unfortunately, we were not able to find adequate Greek literature to compare our study results. When comparing them with international literature, we noted that, although we found no statistically significant differences in the overall incidence of cancer of lymphatic and hemopoietic tissue between the four Greek counties during the two study decades, the overall incidence of leukemia has been declining in the United States. However, recent reports suggest that incidence rates may be increasing for certain age and racial groups (16). Breast cancer mortality is declining in the United States (17-19) and other industrialized areas, possibly due to increased utilization of mammographic screening, early detection of disease and availability of improved therapies. Nevertheless, some European countries such as Spain, Portugal, Hungary, Poland, Italy and Greece, have not reported such positive results. Our results coincide with the above-mentioned, showing an overall statistically significant increase in the PM of the breast and skin in the second study decade compared to the first one.

Finally, our results could also be explained and even biased by factors such as different dietary habits between the four counties, especially comparing rural and urban areas, different lifestyle such as increased stress in urban areas or by changes in dietary habits and smoking between the two study decades, induced by lifestyle changes. The recent adoption of American and Western Europe food habits, with high amounts of polysaturated fatty acids, may affect cancer incidence and mortality data (20). This change has also been prominent in other European countries and a recent study depicted this trend, concerning Denmark and Scotland, between years 1970 to 1999 (21). Water pollution and exposure to insecticides and pesticides could also vary in place and time and could thus explain our results. Finally, our results could also have been affected by the limited observational time period, since some types of cancer might need a longer time period in order to become clinically detectable, as well as by the choice of these particular decades per se.

\section{CONCLUSION}

We recorded statistically significant differences concerning the incidence rates between four different counties as well as between two different decades. It seems that counties of Northern Greece and, in particular, Thessaloniki compared to Attiki, have greater PMs than Southern Greek counties during the decade 1989-1998. The data we analyzed are not sufficient to draw definite conclusions concerning the etiology. More studies are needed in order to reveal other potentially more important genetic or environmental factors that could be responsible for the increase of the PMs.

\section{REFERENCES}

1. Levi F, Lucchini F, Negri E, La Vecchia C. Worldwide patterns of cancer mortality, 1990-1994. Eur J Cancer Prev. 1999 Oct;8(5):381-400.

2. Greek National Statistical Service Population Data Report - Years 1979-1998.

3. Mettlin C. Global breast cancer mortality statistics. CA Cancer J Clin. 1999 May-Jun;49(3):138-44.

4. Groves FD, Page WF, Gridley G, Lisimaque L, Stewart PA, Tarone RE, et al. Cancer in Korean war navy technicians: mortality survey after 40 years. Am J Epidemiol. 2002 May 1;155(9):810-8.

5. Van Wijngaarden E, Nylander-French LA, Millikan RC, Savitz DA, Loomis D. Population-based case-control study of occupational exposure to electromagnetic fields and breast cancer. Ann Epidemiol. 2001 Jul;11(5):297-303.

6. Harlap S, Olson SH, Barakat RR, Caputo TA, Forment S, Jacobs AJ, et al. Diagnostic X-rays and risk of epithelial ovarian carcinoma in Jews. Ann Epidemiol. 2002 Aug;12(6):426-34.

7. Asp S, Riihimaki V, Hernberg S, Pukkala E. Mortality and cancer morbidity of Finnish chlorophenoxy herbicide applicators: an 18-year prospective follow-up. Am J Ind Med. 1994 Aug;26(2):243-53.

8. An SAB report: assessment of potential 2,4-D carcinogenicity: review of the epidemiological and other data on potential carcinogenicity of 2,4-D by the SAB/SAP Joint Committee. Washington: United States Environmental Protection Agency; 1994. Report No. EPA-SAB-EHC-94-005.

9. Acquavella J, Olsen G, Cole P, Ireland B, Kaneene J, Schuman S, et al. Cancer among farmers: a meta-analysis. Ann Epidemiol. 1998 Jan;8(1):6474.

10. Wynder EL, Cohen LA, Muscat JE, Winters B, Dwyer JT, Blackburn G. Breast cancer: weighing the evidence for a promoting role of dietary fat. J Natl Cancer Inst. 1997 Jun 4;89(11):766-75.

11. Trichopoulou A, Katsouyanni K, Stuver S, Tzala L, Gnardellis C, Rimm E, et al. Consumption of olive oil and specific food groups in relation to breast cancer risk in Greece. J Natl Cancer Inst. 1995 Jan 18;87(2):110-6.

12. Clavel-Chapelon F, Niravong M, Joseph RR. Diet and breast cancer: review of the epidemiologic literature. Cancer Detect Prev. 1997;21(5):426-40.

13. Willett WC. Fat, energy and breast cancer. J Nutr. 1997 May;127(5 Suppl):921S-923S.

14. Rose DP. Dietary fatty acids and prevention of hormone-responsive cancer. Proc Soc Exp Biol Med. 1997 Nov;216(2):224-33.

15. Greenwald P, Sherwood K, McDonald SS. Fat, caloric intake, and obesity: lifestyle risk factors for breast cancer. J Am Diet Assoc. 1997 Jul;97(7 Suppl):S24-30.

16. Xie Y, Davies SM, Xiang Y, Robison LL, Ross JA. Trends in leukemia incidence and survival in the United States (1973-1998). Cancer. 2003 May 1;97(9):2229-35.

17. Chu KC, Tarone RE, Kessler LG, Ries LA, Hankey BF, Miller BA, et al. Recent trends in U.S. breast cancer incidence, survival, and mortality rates. J Natl Cancer Inst. 1996 Nov 6;88(21):1571-9.

18. Wingo PA, Ries LA, Rosenberg HM, Miller DS, Edwards BK. Cancer incidence and mortality, 1973-1995: a report card for the U.S. Cancer. 1998 Mar 15;82(6):1197-207.

19. Tarone RE, Chu KC, Gaudette LA. Birth cohort and calendar period trends in breast cancer mortality in the United States and Canada. J Natl Cancer Inst. 1997 Feb 5;89(3):251-6.

20. Kromhout D, Menotti A, Kesteloot H, Sans S. Prevention of coronary heart disease by diet and lifestyle: evidence from prospective cross-cultural, cohort, and intervention studies. Circulation. 2002 Feb 19;105(7):893-8.

21. Kesteloot H. Differential evolution of mortality between Denmark and Scotland, period 1970 to 1999 . A comparison with mortality data from the European Union. Eur J Epidemiol. 2006;21(1):3-13. 